SISTEMA
ELETRONNICO
DE REVISTAS
SER I UFPR

\title{
Abordagem territorial para a Geografia Marinha: reflexões a partir do planejamento espacial e a gestão integrada
}

\section{Territorial approach to Marine Geography: preliminary reflections since the spatial planning and integrated governance}

\author{
Daniel Hauer Queiroz TELLES ${ }^{1^{*}}$ \\ ${ }^{1}$ Centro de Estudos do Mar (CEM), Universidade Federal do Paraná (UFPR), Pontal do Paraná, PR, Brasil. \\ *E-mail de contato: danieltelles@ufpr.br
}

Ensaio recebido em 11 de maio de 2018, versão final aceita em 6 de novembro de 2018.

RESUMO: $\quad$ Este estudo visa contribuir com a elaboração conceitual para o campo de atuação da Geografia Marinha. Pesquisas geográficas sobre espaços marinho, costeiro e oceânico têm predominado desde abordagens sobre fenômenos físicos. Tais avanços vêm resultando inequívocas contribuições no âmbito das políticas públicas no Brasil. Com a intensificação da urbanização, dos modos de produção e dos fluxos de objetos e ações, as interrelações sistêmicas e decorrentes implicações ambientais consolidam a interferência antrópica nos mares, oceanos e costas. Convém, então, considerar-se uma condição territorial a esses espaços. Os fatores de ênfase humana (econômicos, políticos, culturais) configuram, também, o quadro complexo de ações sobre as superfícies marinhas, contribuindo para que as mesmas sejam influenciadas por valoração, apropriação, usos, conflitos e atividades. As múltiplas escalas cabíveis à inteligibilidade da superfície terrestre projetam na superfície marinha uma superação paradigmática, aqui atribuída à Geografia Marinha. Ao passo em que surge um crescente foco na atribuição de responsabilidades sobre os litorais, as zonas contíguas e as águas internacionais, sob preocupação de fóruns multilaterais cada vez mais criteriosos, a governança acaba por evidenciar o desafio de se construir consensos, normas, agendas e avanços em propósitos sustentáveis. Conceitos como o de território, por sua vez, contribuem com as abordagens complexas inerentes às questões emblemáticas de tais áreas. Algumas proposições da Geografia contemporânea, em permanente (des) construção, podem auxiliar no aprimoramento de métodos e técnicas de abordagens, pesquisas e aplicações do conhecimento geográfico para oceanos e costas. O desafio está em aproximar linhas de pensamento e de trabalho, o que incorre em um caminho de diálogo necessário dentro da própria constituição e consolidação da Geografia Marinha, em seu alcance metodológico para a integração dos fenômenos físicos e humanos. A(s) cenda (a)o debate.

Palavras-chave: geografia marinha; abordagem territorial; desafios entre ciência e gestão. 
ABSTRACT: This study aims to contribute with the conceptual elaboration for the field of marine geography. It recognizes that it is a complex and unusual front to this line of research, but it is justified by the need to improve the integration between science and management for coastal and oceanic spatialities: a central aspect in the premises of Marine Spatial Planning and Integrated Coastal Management. Geographical surveys in these spaces have predominated from dynamic approaches on physical phenomena - geological, climatic, geomorphological and / or oceanographic. These advances have resulted in unequivocal contributions in the scope of public policies in Brazil. With the intensification of urbanization and the flow of objects and actions, systemic interrelations and resulting environmental implications, the intensification of anthropic interference in the seas, oceans and coasts extends to a territorial condition to these spaces. Although distant, the diverse motives of human emphasis (economic, political and / or cultural) configure the complex framework of actions on the areas that are object of the Marine Geography and contribute to them to increase valuation, appropriation, uses, conflicts and activities on multiple scales. Whereas the focus on the allocation of responsibilities to the coastlines, contiguous zones and international waters increases under the concern of judicious forums, the governance ends up highlighting the challenge about consensus, norms, agendas and advances sustainable purposes. Some concepts such as scale, region, place, territory and frontier, in turn, are able to contribute to the complex approaches inherent in the emblematic issues of such spaces. Some proposals of contemporary Geography, in permanent (dis)construction, can help in the improvement of methods and techniques of approaches, researches and applications of geographic knowledge for oceans and coasts. It is a challenge, however, to bring lines of thought and work closer together, which implies a necessary dialogue within the very constitution and consolidation of the Marine Geography, in its methodological scope for the integration of physical and human phenomena. To debate.

Keywords: marine geography; territorial approach; challenges between science and management.

\section{Introdução}

A importância de se estar contribuindo com a presente discussão está na busca de ampliação de posicionamento teórico e técnico da Geografia às diferentes expressões em torno da gestão oceânica e costeira. Trata-se de uma lacuna teórico-prática a ser desvendada de modo mais aprofundado (Fletcher \& Smith, 2007). Como pano de fundo, pretende-se estimular um canal de trabalhos versátil e consistente, a partir de aproximações desde a realidade brasileira em estudos e experiências na área, buscando fortalecer o papel da Geografia, inequivocamente necessário para a identificação e o suprimento de lacunas científicas e de governança do território.

Por este caminho serão apresentadas algumas contribuições intrínsecas da disciplina nas diretrizes de governança costeira e oceânica ao longo de seu surgimento e sua evolução. Depara-se com períodos de afirmação de algumas ideias centrais em âmbito internacional, a saber: os direitos territoriais marítimos, o gerenciamento costeiro (integrado) e o planejamento especial marinho (marítimo). Tais ideias tornar-se-iam diretrizes (técnicas) de governança com apelo gradativo em âmbito internacional - ainda que praticadas de maneira heterogênea. Diante desse espectro, em sua amplitude, que aprimoramentos a elaboração analítica e propositiva geográfica oferece ao desafio entre teoria e práxis sobre o espaço marinho?

Não pretendendo gerar certezas, a problematização de fundo a instigar a presente discussão gira em torno da lacuna entre, de um lado, a crescente capacidade de geração de metodologias e 
técnicas de pesquisa para alimentação de bases de dados, monitoramentos e modelagens e, de outro, a não correspondente capacidade de avanços aos processos de gestão que atendam ao crescimento dos desafios socioambientais e ecossistêmicos, em âmbitos local, regional e global. Convém provocar um melhor equacionamento sobre o caráter básico e aplicado da ciência, sobretudo na orientação de problemas e objetivos de pesquisa. Considerando-se a ocorrência de avanços em produção de conhecimento e acumulação de dados, como os processos de governança (em sentido amplo) podem qualificar as relações entre pesquisa e ação prática sobre os sistemas costeiros e marinhos? Que caminhos conceituais interlocutores poderiam suprir essa discrepância? Que sincronias são requeridas entre as escalas de abordagem e as escalas de ação para os fenômenos e/ou objetos de investigação sobre o espaço marinho?

O desafio da contextualização temática espacial para oceanos e costas possui antecedentes, a destacar a superação da concepção tradicional prevalecente até o término da Segunda Guerra Mundial (Mitchell, 1999). Tal contextualização apresenta, desde um viés geográfico, características de abordagens que, por sua vez, vieram a sugerir colaborações à parte analítica e descritiva dos fenômenos físicos. Fato este que, com o surgimento e aprimoramento de áreas afins de conhecimento, passou a exigir da Geografia atualizações e diferenciais teórico-metodológicos para uma nova perspectiva de olhar para o mar (Muehe, 2016). Surgem novas lacunas por abordagens de cunho mais consistentes da relevância conceitual do espaço geográfico e da versatilidade metodológica desta disciplina no tratamento, inevitavelmente complexo, da matéria. É dizer, o conceito de território como categoria espacial, ao enfatizar aspectos sociais, políticos, culturais e econômicos, oferece caminhos às perguntas anteriormente apresentadas, agregando a área de atuação da Geografia Marinha aos desafios da gestão sobre o que é de uso comum.

Para conduzir a presente discussão serão apresentadas quatro linhas de argumentação, por partes. Inicialmente, como plano temático de contextualização da pertinência da presente abordagem, são apresentadas considerações acerca dos aspectos interdisciplinares e complexos inerentes à questão/ abordagem ambiental e sua respectiva governança. A seguir, o contexto de formação e atuação da própria Geografia, em relação às discussões do espaço costeiro e oceânico, atribuídos à linha conhecida como Geografia Marinha. Depois, são dedicadas linhas introdutórias sobre a possibilidade de contribuição do uso de categorias de análise geográficas como ferramentas complementares a conduzir pesquisas em suas complexidades territoriais. Finalmente, também em um panorama de cunho teórico, é apresentada discussão sobre o Planejamento Espacial Marinho e sua contribuição (real e potencial) com a ampliação de suas pretensões, internacionalmente estimadas.

Pretende-se, ao final, demarcar a importância da ciência geográfica e sua contribuição epistemológica a contribuir com a ciência e a governança do espaço marinho. Mais ainda, demonstrar a possibilidade de trânsito permanente entre as dimensões terrestres e oceânicas, para além de abordagens ecológicas ou geofísicas, a partir da compreensão da condição territorial dos mares, das costas e dos oceanos. 


\section{Meio ambiente e governança: interdisciplinaridade e complexidade}

A interdisciplinaridade pode ser entendida como desafio e condição de aproximação entre ciência e política, ou propriamente de uma incorporação da ciência como prática cultural (Floriani, 2004). Processos de cunho ambiental gerados desde a Conferência de Estocolmo vêm ocorrendo, não raramente, desconectados em termos conceituais, tendo ocasionado contingências de origem política e de natureza ambígua (Mello-Théry, 2011). Enquanto que as formulações teórico-metodológicas interdisciplinares tenham adquirido relevância $a$ posteriori (Moraes, 1989), esta inversão da ordem conceptiva custou, e vem custando, muito trabalho pela maneira como a pauta de questão ambiental é conduzida; quase que aleatoriamente, aos sabores plurais de uma corrida cujo ponto de partida é o próprio conceito de meio ambiente. Resulta que o esforço de desconstrução, além de demoradamente iniciado, exige novo tempo de preparação e assimilação para, então, entrar em uma nova vinculação propositiva entre ciência e governança.

Ao mesmo tempo que um aparato metodológico é indispensável, são divergentes os métodos de análise herdados das diferentes ciências que atuam no novo paradigma ambiental. A dificuldade de se avançar é consequência de uma insuficiência de linguagem comum decorrente, entre outros fatores, da pressão internacional que carrega formulações ideológicas e geopolíticas. A diversidade de esforços não tem sido realizada de maneira convergente, resultando em uma impreterível retomada do paradigma complexo inerente à matéria, e reconhecendo a contribuição científica geográfica como papel central no dimensionamento entre linhas de pensamento e de trabalho (Mello-Théry, 2011).

Ao trabalhar na seara disciplinar, seja da interdisciplinaridade por conveniência ou da complexidade como constatação protocolar, ambas possibilitam, não mais do que um diálogo hermético, de domínios de linguagem, jargões e correntes. Ao trabalhar na seara da integração, da transdisciplinaridade como busca e abertura permanentes de novos diálogos, da complexidade como ponto de partida sobre incertezas (Trush, 2016), de sistemas abertos e não-lineares (Chapin III et al., 2009), da adaptação e dialética do método, possibilita-se a ruptura de paradigmas. Resgata-se, assim, a concatenação entre teoria, método, metodologia e técnicas de pesquisa, e assim, a permanente construção de resultados parciais de um processo de inteligibilidade do mundo, que possibilite interação entre ciência e política, para além do registro de dados quantificáveis.

Atuar sobre as lógicas coexistentes no plano da ciência e da governança buscando suas relações de causa-efeito para as questões ambientais e territoriais, é dizer que não se pode trabalhar o paradigma ambiental alheio à realidade, que por si só é complexa (Morin, 2003; 2008). Ainda que se verifique a ocorrência paralela entre posturas científicas e sua função social, a pergunta que pode estar em desaviso é: a ciência que se faz está atingindo e sendo atingida pela governança (práxis), em retroalimentação progressiva? Essa suposta má relação entre ciência e governança pode resultar em uma espécie de alienação proposital, de fazer ciência sem questionar-se para quê? Gera-se o equívoco do que se crê saber com clareza em detrimento do que se necessita saber (Bachelard, 1995). Tal polêmica, embora deva ser relativizada na inequívoca importância de produção científica de base, 
representaria um apelo pela superação axiomática ao desafio transdisciplinar.

A Geografia volta-se, entre outras frentes, para as discussões interdisciplinares em torno das relações sociedade e natureza. Trata-se de um debate recorrente, em que reflexões elevam seu status científico de ideográfico a nomotético, seja pela perspectiva da superfície terrestre como biosfera, hidrosfera ou crosta (Moraes, 1997). Antes mesmo do surgimento dos conceitos de meio ambiente e de sustentabilidade, a ciência geográfica se ocupava em traçar metodologias que unificassem as variáveis físicas e humanas.

Aqui não interessa entrar na história do pensamento geográfico, mas sim destacar a condição recorrente de seu alcance interdisciplinar (Lins-de-Barros \& Muehe, 2009). Para Vallega (1999), a aproximação da Geografia com as Ciências do Mar apresenta três papeis de contribuição, a saber: a discussão epistemológica como embasamento; as interações entre comunidades humanas e ecossistemas; e os esboços de padrões de desenvolvimento. Conforme pretende-se destacar, tais linhas de discussão possuem grande importância na condição dada aos espaços oceânicos e costeiros. É necessário salientar, ao mesmo tempo, as limitações da própria disciplina geográfica em estudos já existentes na transversalidade entre ciência e governança de espaços marinhos e costeiros como abordagem que requer desde suporte de método sistêmico até a consideração sobre processos políticos (Vallega, 1994). Tais lacunas de abordagem podem auxiliar a contribuição de preenchimento de entre o conhecimento e a gestão de tais sistemas (Tintoré et al., 2009).

Admitir que a relação entre ciência e governança tenham um caráter uníssono de direciona- mento de informações (saberes, conhecimentos, avaliações, etc.) é concordar com o distanciamento científico da realidade; é premiar um fazer científico dual e fragmentado em duas dimensões incomunicáveis: mente e matéria (Capra, 2004). Prejuízos à parte, a governança tenderá a enquadrar-se no que se denomina de pós-político, ou seja, uma postura que compartimenta a visão da política em modos de governo, de gerenciamento, ou mesmo policiamento (Ranciére, 2001). A retroalimentação entre as instâncias ciência e governança incorre, assim, em um desafio comunicacional.

Ao adquirir uma revisitação teórica para o objeto da ciência geográfica, considerando-a uma disciplina que deve interferir na história, não somente interpretá-la (Santos, 2008c) e estar à altura da possibilidade de intervenção na transformação da sociedade mediante seu papel ativo das teorias espaciais como suporte à sociedade (Santos et al., 2000), a Geografia inicia um percurso de reaproximação com a realidade, ao longo de suas sucessíveis crises epistemológicas, superadas e superáveis (Soja, 1993). Após longo período voltado à discussão epistemológica, onde foram dirimidos esforços na aproximação com a Economia, a Sociologia e a Filosofia, bem como suas aplicações para diferentes ramos eleitos como prioridade de atuação, no âmbito das políticas de Estado é que o pensamento geográfico surge como modo de prospecção não setorial da organização das atividades e usos do território.

As especificidades do território resultam em muito mais do contato do que do isolamento espacial, isto é, ele também deve ser pensado como produto de inter-relações, de forma que não há um ponto de partida original a ser recuperado ou uma posição anterior à relação (Massey, 2005), mas tão 
somente a relação em si, das múltiplas dimensões de análise das dinâmicas sociais que configuram o território: a política, a econômica e a cultural (Corrêa, 2011). Essa perspectiva de concepção integrada leva em consideração a ideia de totalidade em transformação e abarca mais do que uma coisa ou objeto; o território é um ato, uma relação, um movimento, um ritmo sobre o qual se exerce um amálgama de controles (Haesbaert, 2004), tal qual a diversidade de escalas de operação sobre ele, seja em sua compreensão (ciência) ou em sua intervenção (governança).

Empenhada em desvendar e revisitar o espaço geográfico, seu objeto, a Geografia Marinha abre caminhos para que sejam, a partir deste, realizadas análises em torno do conceito de território no mar e suas espacialidades adjacentes (oceano e costa). A tênue distinção entre espaço e território é de relevância ímpar na composição teórica e aplicação textual que se referem aos diferentes fenômenos que se materializam, sendo o território de uma importância mais aproximada à governança, às intencionalidades e às ações políticas. A intencionalidade enquanto ação acaba por ser mais uma qualidade condicionante da compreensão das dinâmicas que configuram o território, seja ela como premissa ou nas perspectivas compreendidas pelas relações de poder, de apropriação, ou de pertencimento. Está-se diante de espaços que não são inertes, mas vividos (Fremónt, 1980), praticados e gerenciados (Sonnic, 2010), seja em relação às dimensões políticas, culturais ou econômicas: autônomas e interdependentes (Corrêa, 2011).

O espaço é processo permanente de transformação das e pelas sociedades. Estas transformações, com o transcorrer da história, configuram modificações e condições na natureza e no território. Em relação ao território e sua evolução conceitual contemplando a sociedade, tem-se que ele é a cena do poder e lugar de todas as relações (Raffestin, 1993). Tais relações estão na sociedade como um todo em suas diferentes e complementares instâncias; vividas e percebidas e compreendidas diferentemente. De modo que o território passa a ser compreendido como fato social e político (Saquet, 2007). É o uso do território como quadro de vida constante de todos os homens que se contempla o objeto da análise social (Santos, 2008a). Por território usado entende-se o espaço e seu acúmulo histórico de diferentes forças (culturais, econômicas e políticas) e escalas, que acabam por configurar uma relação de poder resultante em estado permanente de transformação.

Se considerada a pertinência de atribuir aos espaços oceânicos um caráter territorial (Grancalanci \& Scovazzi, 1994; Vivero et al., 2010), é possível vislumbrar um fortalecimento nas relações entre ações investigativas e de governança a estes espaços. A partir disto, a produção de conhecimento (estado da arte) poderá aproximar-se às lacunas de conhecimento, propiciando uma inter-relação comunicativa entre ciência e gestão.

Na seara da contribuição geográfica para a ciência e a gestão de mares e oceanos, está a condição territorial predecessora e consecutiva, em constante análise dos processos decisórios: nas normas oficiais ou consensuais, nas infraestruturas, nos fluxos, nas estratégias de exploração ou conservação. Isto amplia a busca de avanços teóricos para a capacidade metodológica da Geografia Marinha, como ciência una e integrativa de fenômenos espaciais físicos e humanos. Não está, portanto, somente a encargo das abordagens de ênfase ambiental, a abordagem territorial sobre a gestão de mar e costa. 


\section{A transformação da Geografia Marinha}

A posição da Geografia Moderna (Moraes, 1989), em relação aos estudos do mar e do oceano, tem sido influenciada pela própria acepção da história do pensamento geográfico, da evolução do meio técnico-científico e da especialização de disciplinas afins. Se considerados os problemas associados aos usos do mar e a contribuição da geografia perante esses problemas, é possível perceber desajustes na capacidade de dar respostas ao espaço oceânico (Vivero, 1979; Mitchell, 1999). Fato que trouxe à tona a problematização sobre a necessidade de retomada de um espaço perdido (Muehe, 2016).

O reconhecimento da existência e importância da espacialidade costeira e oceânica passa a ser importante aspecto na afirmação do objeto da Geografia Marinha. Seu tratamento, no entanto, não transcende sem dificuldades em relação ao caráter integrado, ou seja, em sua totalidade. Existe, pois, uma questão de método em tela a ser ajustada. Segundo N. Broc (1974), uma das principais dificuldades da Geografia foi superar as restrições que o espaço habitado pelo homem impunha à disciplina. Desde a diferenciação de áreas, em que a preocupação com a superação da mera descrição espacial da superfície terrestre (paisagem), até a mediação técnica e política do homem sobre esta superfície, a Geografia investiu gerações e escolas de conhecimento, cada vez mais exigida em abrir-se aos desafios de transcender à constatação e ao reconhecimento da interdisciplinaridade.

A partir da ampliação dos usos sobre mares e oceanos, interesses geopolíticos passariam a estabelecer as concepções de natureza de tais espaços. Os conflitos de interesse entre nações marítimas passariam a resultar em conceitos pretensamente universais sobre o caráter patrimonial ou não dos mares, a partir das proposições de mare liberum $\mathrm{e}$ mare clausum, no Século XVII.

Assinalado por F. Ratzel (1907) como via, o espaço marítimo poderia ser tratado apenas pela geografia da circulação, uma vez que as tentativas de o dominar política e economicamente eram efêmeras, abstratas. H. Mackinder (1942) vai adiante nessa concepção, atribuindo a um poder sobre os fluxos marítimos a condição de se contar com uma base territorial continental/emersa. Com M. Sorre (1954), o espaço marítimo passa a ser considerado ao uso social em si mesmo, e de caráter permanente, ao reconhecer as rotas oceânicas como significação geográfica de notória importância. Seu controle estaria atrelado a um Estado soberano, resolvendo a questão sobre as extensões oceânicas pertencerem ou não ao domínio antrópico (Vivero, 1979).

As pesquisas geográficas sobre os oceanos, embora estivessem presentes desde o século XIX, ocorreram gradualmente em menor proporção do que as pesquisas geográficas em áreas continentais. Teria esse aspecto condicionado um distanciamento entre as abordagens geográficas das demais disciplinas (geofísicas, bioecológicas, oceanográficas)? Se sim, o que acarretou em cunho epistemológico para ambas as disciplinas, mas principalmente, para sua relação interdisciplinar?

As abordagens do espaço marinho na geografia tiveram ênfase durante os terços final do século XIX e inicial do século XX, portanto desde uma perspectiva da ciência clássica. Com exceção de atuações com ênfase na Geografia Física, verificou-se baixa participação geográfica nos estudos científicos dedicados ao mar, após esse período (Lins-de-Barros $\&$ Muehe, 2009). Tal distanciamento refletiu-se na 
menor evolução epistemológica, fruto de debates científicos, sobre os litorais ou zonas costeiras, que presenciaram uma produção de conhecimento aquém, em relação a outras espacialidades de hinterlândia - seja das ruralidades, do urbano, das áreas protegidas, fronteiriças, entre outras. O caráter espacial dos oceanos, mares e litorais teve, em uma perspectiva geral, uma promissora gênese integrada entre abordagens físicas e humanas. Teria, contudo, evoluído com ênfases nos fenômenos físicos e naturais, em detrimento de abordagens aos fenômenos humanos. O debate territorial teve menor avanço.

Considerando o contexto litorâneo, podemos alegar que foi na funcionalidade portuária que o conhecimento geográfico se aprimorou em análises idiográficas. Isto se deu, no continente americano, pelos interesses coloniais a partir do século XVI, quando diferentes bandeiras disputavam as regalias oriundas do novo mundo e em tais empreitadas estava a estratégia de dominação de locais de melhores condições de atracagem, a saber, os portos naturais (Ab'Saber, 2006; Hutter, 2005; Staden, 2009).

A perspectiva espacial descritiva parte da apreensão do sítio enquanto suporte primário para as dinâmicas espaciais. O local apropriado para a localização ou ocorrência de dado fenômeno terá uma área de influência no sentido aquático e/ou terrestre, por onde são ocasionadas dinâmicas territoriais (Sonnic, 2010; Telles, 2012). É na correlação do conceito de território que a geografia avançou sua atuação nesses, até então, sítios. Isto convergiu com a ascensão da importância e necessidade de ordenamento territorial dos Mares Territoriais e de apropriação das Zonas Econômicas Exclusivas em cada espaço nacional, de um modo geral.

A abordagem sobre usos atrelados aos espaços marinhos existe em termos setoriais, tais como transporte de cargas, exploração minero energética, pesca e aquicultura e fins militares (Da Pozzo, 1987). Integrar esses setores consagrados com realidades mais próximas da escala local, em que estejam inseridos fenômenos como o cotidiano das cidades marítimas, o modo de vida de comunidades tradicionais ou o turismo de massa, é um desafio que a abordagem territorial complexa visa sustentar. Sob o viés da Geografia contemporânea, as escalas, a partir de uma perspectiva que será discutida a seguir, estão inerentemente conectadas desde a abordagem até a projeção.

A questão fundamental, embora de amplo sentido, é a de considerar o oceano não apenas como parte da hidrosfera, mas da superfície terrestre (Muehe, 2016), uma espacialidade dotada de suas próprias lógicas de compreensão dentro do arcabouço teórico que torna a sociedade da natureza indissociável.

No Brasil, a atuação denominada Geografia Marinha possui potencial de ampliação de rede de pesquisa e aprofundamento epistemológico, abrindo-se ao debate teórico sobre o ordenamento territorial à faixa marinha em direção ao oceano. A geração de debates complexos que gerem conhecimentos sobre a interação do homem com o oceano e de ação política sobre o ambiente marinho (Muehe, 2018). O conhecimento geográfico pode ir adiante na contribuição de pesquisas sobre as diferentes escalas e territorialidades e seus respectivos usos, conflitos e complementaridades. Trata-se de um desafio ao interesse pelo campo científico, para além dos direcionamentos setoriais econômicos ou estratégicos dentro das agendas do Estado, em suas devidas importâncias e limitações. 


\section{Escala geográfica-territorial: a complexidade do terrestre e a complexificação do marinho}

A escala se constitui numa preocupação metodológica fundamental às análises espaciais dos sistemas terrestres. Preocupação porque não é um conceito estático; fundamental porque sem ela, o objeto espacial exime-se de representação empírica. Apesar de seus diferentes enfoques, ela não existe apenas como medida, porque não fragmenta, pelo contrário, integra (Castro, 1993). Ao constituir-se em uma aproximação do real, a escala não restringe à métrica de proporção. Para a abordagem espacial em sua totalidade, torna-se ainda mais desafiador apresentar-se como categoria de análise convergente, seja dos fenômenos naturais ou sociais; físicos ou humanos. Tal dissociação é ação que desintegra, e pode servir utilmente para fins técnicos e disciplinares, mas apresenta limitações em situações complexas e abordagens holísticas, sistêmicas e adaptativas.

Para Corrêa (2011), "a operação escalar não introduz uma visão deformada, geradora de dicotomias, mas ao contrário, ressalta as ricas possibilidades de se analisar o mundo real [...] em níveis conceituais complementares" (p. 136). A convergência entre escalas de abordagem caracteriza a apreensão do objeto investigado. São as conexões que se fazem possíveis identificar entre as escalas que "contribuem para dar unidade à análise geográfica" (p. 136).

A escala geográfica, considerada a pertinência de um fenômeno observado (Castro, 1993), extrapola o uso aprisionado de abstração reduzida do real, possibilitando tratamento que dê conta da multiplicidade e da diversidade de situações e de processos (Santos, 2008b). A partir do instante em que a pesquisa assuma a visão sistêmica e aberta, a escala surge como ferramenta em dois momentos: na abordagem e na projeção. Ambos implicam em seleções de variáveis, as quais requerem abertura de recortes como fator de dinamicidade permanente na integração das variáveis, também descobertas de garantia estática. A escala geográfica é o reconhecimento do tratamento intencional sobre algum objeto no espaço terrestre, tendo assim uma função, um uso territorial. É uma abordagem geográfica-territorial de abordagem e projeção.

O enfoque da escala é múltiplo, pois um mesmo recorte espacial pode receber tantas quantas forem possíveis as abordagens e projeções: seja em distância ou em perspectiva. Se a visão microscópica permite a compreensão dos detalhes e da organização localizada, para captar a complexidade das organizações que extrapolam os locais, as regiões, e até mesmo grandes extensões de cobertura da superfície do globo terrestre, se torna necessária uma visão macroscópica (Machado, 1995). E é nessa interação entre local e global que a escala geográfica se torna complexa, seja nas interferências de ordem planetária em qualquer pequena porção de superfície terrestre (Swyngedouw, 1997; Smith, 2002), ou ao instrumentalizar a compreensão de fenômenos espaciais, sobretudo os não fixos. A coexistência dessa multiplicidade de olhares expressa a complexidade da análise ao espaço marinho e seus inúmeros desdobramentos.

Atribuir à escala uma perspectiva não matemática é ampliar suas possibilidades de análise e proposição. Trata-se, sobretudo, de um redimensionamento desta categoria para os desafios éticos, políticos e científicos contemporâneos às Ciências 
da Terra (Peppoloni \& Di Capua, 2015). Não se exclui a importância técnica de geração de conhecimentos pragmáticos ou projetados, ainda que estes devam ser relativizados em suas pretensões, tendo em vista as repercussões ideológicas e o caráter de poder e controle das representações espaciais, sobretudo cartográficas (Harley, 1988).

Se constatada a preocupação de que a própria escala enquanto procedimento de análise mereça ser estudada de modo particular, por mediar uma ação (Racine et al., 1983, p. 124), a relação entre o fenômeno observado e sua abordagem requer esclarecimentos sobre essa intenção metodológica em dois momentos: a abordagem da realidade e a projeção da análise. Incorrem nos esforços e nas intenções da pesquisa, em sua elaboração e em sua divulgação. Há um viés científico e um político, com os quais a Geografia já teve a experiência de atuar conjuntamente em esforços e experiências (Lacoste, 2010).

\section{Governança territorial marinha e costeira: superações em teoria e práxis}

A política pública diretamente associada a esse conhecimento, o Gerenciamento Costeiro, possui 30 anos (Brasil, 1988) e se encontra em panorama assimétrico em relação aos seus estados e municípios costeiros (Nicolodi et al., 2018). Os incentivos dirigidos por parte do Estado brasileiro, nas décadas de 1980 e 1990, possibilitaram o despertar de interesses de diferentes frentes acadêmicas pela matéria, na busca por produtos oficiais de nível macroescalar (Brasil, 1996), ou no direcionamento da governabilidade para a faixa de orla (Brasil, 2004; 2005; 2006a; 2006b; 2006c). Os instrumentos, programas e agendas do Gerenciamento Costeiro oferecem diversificadas possibilidades analíticas e práticas, uma vez que lidam com territórios e territorialidades múltiplos em suas extensões. A seguir, algumas considerações de nível teórico que possam contribuir para este debate, ainda que de modo menos pragmático que reflexivo. No fundo, tal reflexão pretende a(s)cender o debate que fomente a capacidade executiva de transformações no gerenciamento costeiro, através da governança de viés complexo e em múltiplas escalas.

A governança entendida como ação e incumbência territorial transcende para um conceito mais permeável às dinâmicas resultantes das ações dos grupos sociais, em que se admita a sociedade civil de um território como uma das fontes de poder nos processos de governança (Dallabrida, 2007). A necessidade de avanços escalares de aplicação da gestão carece de avanços, que também é um fator limitante para as escalas de abordagem científica. Há um predecessor uso da escala como campo de ações político, no interesse hegemônico (Acselrad, 2002). Por antítese, o uso da escala como campo de ações da ciência poderia prover o interesse orgânico dos territórios. De modo que a práxis tecnocrática de Gerenciamento Costeiro (instrumentos), por exemplo, fosse melhor estimada pela equivalente busca por inteligibilidade sobre a práxis territorial (agendas). Como hipótese dessa promoção de ambas as frentes analíticas, a efetividade de programas seria elevada.

Ao superar a sua concepção como mera atribuição do Estado, ainda que se ampliada a noção deste último, possibilita um alcance conceitual de maior envergadura para fenômenos integrados e complexos, sem ignorar a existência de mecanismos de construção de institucionalização da exclusão 
(Burtzyn, 2009; Cleaver, 2005; Fuks \& Perissinotto, 2006). O envolvimento da sociedade no processo da governança é um requisito em que sejam permitidos, possibilitados, incentivados e aprimorados diferentes mecanismos de formação de consensos flexíveis e atrelados aos grupos sociais e seus saberes (Holling et al., 1998; Carlson \& Berkes, 2005; Medeiros, 2009).

Admite-se que a legalidade da governança deve ser não apenas reconhecida oficialmente como princípio, mas executada por agendas; assim irá depender do modelo democrático em vigência (Inadmar et al., 1999) e os interesses de Estado não comprometidos pelos interesses de Governo, que possuem prazos distintos. Eis o envolvimento entre a gestão pública convencional (protocolar) e a prática de governança participativa (Grindle, 2007), dinâmica. A operação da governança territorial é, pois, multiescalar, uma vez que fatores de ordem local, regional e global encontram-se em relação dialética de contradição de olhares sobre a realidade, mas não sem que essas variáveis múltiplas construam o processo inconcluso de ascensão de um terceiro incluído sobre diferentes níveis de realidade (Nicolescu, 1999) que implica interesses e tomadas de decisão, em que o conflito é a incapacidade gestora materializada e, portanto, ausência de governança, uma vez que a gestão operacional de programas e instrumentos não atende à gestão de agenda, que contrapõe o fato situacional de interesses de governo. Fato ainda a ser aprimorado é a admissibilidade de um sistema de governança em que os diferentes atores do processo estejam equilibrados legitimamente e atendidos de forma menos controversa.

A governança do espaço marinho no Brasil está intimamente ligada às políticas ambientais.
Trata-se de um processo decorrente da aproximação da governança à esfera do desenvolvimento sustentável, apontando para uma delimitação temática da governança mais ampla (Fonseca \& Burstzyn, 2009). O surgimento de aparato normativo nas décadas de 1980 e 1990 auferiu esta aproximação no arcabouço legal dos territórios costeiros, e em menor grau, marinhos e oceânicos, em que a avançada conceituação de um Sistema Nacional de Meio Ambiente fosse acompanhada de agendas executivas para a práxis, mas também expondo lacuna às análises científicas. Estas se voltam aos instrumentos (ênfase no ZEEC) e programas (ênfase no Projeto Orla) de Gerenciamento Costeiro, e observam inovação metodológica das construções participativas, sobretudo no que diz respeito às avaliações sobre Governança de Unidades de Conservação (Abrahão \& Asmus, 2018; Prestes et al., 2018; Sousa \& Serafini, 2018), ou atividades econômicas portuária, pesqueira e turismo.

Na prática, a governança pode ser mais ou menos efetiva, uma vez que opera à margem de atuação dos entes federativos e suas estruturas institucionais em recursos humanos, onde se nota gradativo desmando ambiental (Silva \& Pellin, 2015). Neste sentido, os coletivos designados formalmente para operar as diferentes atribuições de governança costeira e oceânica se veem, muitas vezes, fragilizados em relação à própria incipiência inteligível de tais espaços, em seus fenômenos, também associados aos interesses mandatários de governo, em suas respectivas esferas administrativas.

Trata-se de um desafio sensível à governança o alcance de capacidade de gestão para locais no litoral brasileiro, sob a forma de conselhos, ou órgãos consultivos-deliberativos (Brasil, 1981); seja sob o ponto de vista de sua efetividade, como visto ante- 
riormente, ou da composição e representatividade de tais organismos (Telles et al., 2011). Dentre os elementos que resultam tal desafio, está a adequação de métodos de trabalho aproximados da geração de informações subsidiárias, em suas diferentes expressões. Além do conhecimento técnico-científico existente, para cada contexto geográfico, sob diferentes expressões de diagnósticos disciplinares, temáticos ou projeções cartográficas e tabulações estatísticas, é preciso transcender a contribuição do conhecimento para a governança. É neste ponto que se acredita que a Geografia Marinha possa ampliar sua função científica.

A questão dos diferentes usos sociais que ocorre no espaço marinho é inerente à sua condição territorial. Complexa e multiescalar, além de processual e adaptativa às relações de força, mais ou menos visíveis, legítimas ou deliberadas, que atuam no território. Os fenômenos humanos, em suas diferentes dimensões política, econômica e cultural, constituem-se nas variáveis solidárias e/ ou conflitantes que implicam no desafio da governança territorial. A dupla condição de inteligibilidade e operacionalidade estão intimamente ligadas ao território a ser ordenado. Escalas e dimensões caminham juntas na trama complexa de análise e prática; ciência e governança. Isso não é diferente para os espaços terrestres e oceânicos, ainda que metodologias, bases conceituais e composições interdisciplinares venham a constituir elaborações a parte.

As normatizações dos espaços costeiros e oceânicos requerem desde produtos diagnósticos sobre variáveis físicas de sustentação técnica até modelagens integradas de regionalização e de zoneamento. Aspectos sazonais estão entre os principais obstáculos técnicos do exercício de governança em espaços marinhos. Este desafio, sobre as margens incertas do processo temporal inerente na natureza dos fenômenos, também é científico, e superações de ambas as agendas (pesquisa e práxis) podem ser verificadas no estreitamento e melhor entendimento dos estudos sobre as mudanças climáticas. Para a ação política, importa que seus produtos executivos (obras, normas, fluxos, regulação, incentivos, agendas) sejam contextualizados no espaço, no tempo e na sociedade. Portanto, a adaptabilidade transcende os processos físicos-climáticos-oceanográficos e pode ser compreendida como maneira de analisar as manobras políticas inequívocas que influenciam nas práxis da gestão costeira, em suas diferentes escalas.

\section{A questão espacial para o Planejamento Marinho}

Por definição, o Planejamento Espacial Marinho (MSP) constitui-se em um instrumento de execução da política marítima integrada (Comission of the European Communities, 2008). Tem como objetivo regulamentar e garantir usos e atividades dos ambientes marinhos. É voltada à adoção de uma visão holística e sistêmica que permita a exploração e usufruto dos recursos e territórios com a minimização dos impactos ambientais (Pickaver et al., 2007). Por esta noção pode-se ampliar para ações humanas tangíveis ou não tangíveis, nos espaços marinhos. Fato que torna menos simples a relação causa-efeito na compreensão do amálgama da configuração territorial.

A existência de atividades sociais, simbólicas e econômicas nos mares e oceanos resultam em diversidades que se apresentam sob práticas políticas, culturais e econômicas, de modo geral (Diegues, 
2004). Considerando que tais práticas podem ser associadas às dimensões territoriais anteriormente descritas (Haesbaert, 2004), elas correspondem, ainda que em nível amplo, aos modos de governo, de vida e de produção. Do ponto de vista dos modos de vida, as variáveis que representam as relações da sociedade em diferentes contextos históricos e locacionais, também estarão, de alguma forma, atribuindo função ao espaço marinho - até mesmo na perspectiva de uma cultura de consumo de massa e globalizada. Para os modos de governo, além dos padrões gerais usualmente conhecidos, é possível ampliar para especificidades de cada realidade local e empiricamente observada. Modos de produção afetam o espaço marinho em suas etapas de produção, distribuição e consumo. Isto incorre em reconhecer que, em qualquer das fases produtivas em que ocorra a função de suporte do mar, este se apresenta como território usado, portanto.

$\mathrm{O}$ incremento e as transformações de tais práticas ocasionaram a competição entre usos de diferentes interesses, como a pesca, aquicultura, transporte, portos marítimos, ciência, entre outros. Somado a isto, as constatações sobre problemas ambientais decorrentes, tais como o aumento do nível do mar, a acidificação, o aquecimento das águas e o aumento na frequência de eventos extremos, exigiram medidas políticas comuns no âmbito dos países da UE. Não obstante, os acordos assinados no Livro Azul passaram a requerer um instrumento base de execução das políticas de cada país, resultando no MSP (Comission of the European Communities, 2008).

$\mathrm{Na}$ constituição de um arcabouço conceitual para o Planejamento Espacial Marinho estão inerentes as propriedades brevemente elucidadas sobre $\mathrm{O}$ objeto central da ciência geográfica: o espaço. Con- siderando-se, assim, que o mesmo é condicionado gradativamente pelas ações humanas e que estas resultam intenções, então se torna imprescindível a capacidade analítica sobre as dimensões sociais que resultarão na permanente (re)organização do território marinho, ainda que sob lógicas predominantemente de fluxos.

A apresentação de abordagens que enfatizem dinâmicas sociais sobre o espaço marinho não é considerada predominante em relação às biofísicas, em termos científicos (Teh \& Teh, 2011; Medeiros et al., 2014). O espaço como objeto da Geografia Marinha pode ser uma oportunidade de integração entre tais abordagens, como própria essência da disciplina. O interesse científico em elucidar lacunas já se constitui em uma abordagem social sobre o espaço marinho, como apontada na discrepância de integração de bases de dados do MSP (Gandra et al., 2018).

Em relação ao planejamento, a compreensão exige certo desprendimento dos padrões mais usuais de demarcação de documentos datados em agendas de convenções. Isto é necessário, mas não o suficiente. O planejamento deve estar ciente de sua incompletude sobre o ideal almejado. Por uma questão histórica, trata-se de um processo analítico pari passo à avaliação do que quer que se adote como objeto espacial. É, o planejamento, um ente unicamente prospectivo, ou deve estar em permanente avaliação, a partir do que ele propõe a tratar? Dialético e adaptativo o tornam - o planejamento - inerentemente complexo, para o território.

O planejamento se posiciona como um âmbito de práticas humanas a qualquer atividade prospectiva entre a aventura e o cálculo (Massé, 1967). Nesse entremeio de risco e suposta exatidão, o planejamento se porta como algo dinâmico e não convém 
ser deixado de lado por conta de possíveis desacertos. O planejamento é considerado um instrumento da política. Não se deve prover o planejamento em horizontes temporais muito curtos, devendo ser contado o plano de organização do território, por decênios (Yázigi, 2005). Atende às questões sociais passíveis de serem relacionadas ao interesse comum e, por isso, é atingido por conflitos sobrepostos que transitam entre escalas e contextos que se diferem para cada fenômeno e realidade. Tais embates podem ser mais ou menos entendidos e, sob aspectos ideológicos, teóricos, técnicos e operacionais, se manifestar na organização do território, tendo o Estado um papel central na elaboração de diretrizes e normatizações gerais em cada esfera oficial.

A possibilidade de enriquecimento metodológico do planejamento espacial exige que sejam levadas em consideração os âmbitos multidimensional e operacional em que interagem as estruturas econômicas, geográficas, sociais e políticas (Santos, 2003). Nas dimensões economia, política e cultura estão compreendidos os percursos analíticos para a identificação do caráter territorial do objeto. Possivelmente uma abordagem inexistente no seio da Geografia Marinha, em sua complexidade e tendo o território como ente central da análise espacial. Veja-se, de modo geral, as dimensões economia, cultura e política enquanto subsistemas de pesquisa geográfica para mares, costas e oceanos.

Ao final, planejar as variáveis humanas sobre mar e oceano deve ser a atribuição do Planejamento Espacial Marinho, não sem reconhecer seu objeto geograficamente. Não resta dúvida de que se está diante de um sistema bastante amplo de trabalho e ação, que desafia a lacuna entre proposição teórica e vontade política no contexto internacional, atribuindo-lhe uma ferramenta fora da realidade
(Plasman, 2008). Fato este que a leva a um campo de ação mais ativa no âmbito dos debates, do que executivo. Tratando-se de políticas públicas de Estado, é sugerido que pode estar carecendo base conceitual geográfica territorial, que enriqueça as metodologias das mencionadas ações. É um campo fértil e desafiador, em que a Geografia Marinha se coloca a serviço da ciência e da gestão pública.

\section{Considerações finais}

Entre a geração de conhecimento e a governança do território marinho e suas adjacências (oceano e costa), a Geografia possui contribuições teóricas a serem aproveitadas. Ainda que tenha contribuído na orientação técnica de delimitações espaciais em políticas nacionais, há um horizonte de novas demandas sobre os instrumentos de gestão ilustrados neste artigo (Gerenciamento Costeiro e Planejamento Espacial Marinho) que podem ser redimensionadas, a partir de contribuições contemporâneas da Geografia, sobretudo em sua vertente de abordagem Humana. Se reconhecidas as contribuições advindas das relações entre conhecimento geográfico e governança marinha, considera-se que a complexidade dos diferentes fenômenos que ocorrem nos espaços costeiros e oceânicos sejam objetos de abordagens orientadas às perguntas acerca dos problemas contemporâneos, inevitavelmente complexos. O conceito de território se torna central neste contexto, a ser incorporado na especialidade da Geografia Marinha.

De início, torna-se indispensável a visão sistêmica, propiciando a compreensão inseparável entre oceanos e continentes e entre múltiplas escalas de apreensão dos fenômenos que ali ocorrem. Este fato 
não resulta em facilitador das práticas em pesquisa e em governança que, para as duas superfícies, são bastante específicas em termos paradigmáticos entre outros fatores, pela natureza da propriedade de tais espaços. Ainda assim, tais áreas não deixam de ser complementares e a experiência geográfica de permanente campo voltado às relações entre fenômenos naturais e humanos na organização espacial e nos usos do território pode ser incorporada em maior profundidade na ascensão do Planejamento Espacial Marinho.

Apreendendo as diferentes dinâmicas que ocorrem em ambos os recortes e envolvam direta ou indiretamente a sociedade, está propiciado o campo de análise geográfica, em que as dimensões e escalas sejam integradas na busca pela inteligibilidade dos problemas identificáveis. O espaço é conceito fundamental para a interlocução entre ciência e governança dos oceanos e costas. É necessário, entretanto, que não seja separado de sua natureza geográfica.

A contribuição do que se reconhece como Geografia Marinha é de natureza científica latente a potencializar a inteligibilidade de fenômenos e processos no espaço marinho, no âmbito da qual os aspectos físicos e humanos, em seus múltiplos desmembramentos, visam estabelecer a reafirmação e renovação de seu objeto, a que D. Muehe atribui como sendo um espaço perdido. Ao receber a oportunidade de redimensionamento sobre suas discussões (ciência Geográfica) em períodos inconstantes de, ora ascendência, ora marginalidade institucional no âmbito das políticas de Estado brasileiras, a contribuição teórica desta disciplina reposiciona-se ao Gerenciamento Costeiro e ao Planejamento Espacial Marinho, oferecendo arsenal teórico para um paradigma transdisciplinar (Nicolescu, 1999) fértil a futuras pesquisas atendendo ao enfoque crítico-propositivo e abordagens complexas. Este movimento não é, senão, um caminho de processos científicos e políticos à matéria, em múltiplas escalas territoriais.

Diante de um caminho conector que não parece estar suficientemente elaborado entre ciência e governança do território marinho, é mister a tomada de consciência da importância permanente de retroalimentação comunicativa entre ambas as esferas. Sobretudo no que diz respeito a aplicação do conhecimento à governabilidade $\mathrm{e}$ as problemáticas de gestão cabíveis ao tratamento/acompanhamento científico. Canal de relação entre campos de conhecimento e de ação inequivocamente importantes e necessários para a identificação e o suprimento de lacunas científicas e de governança.

\section{Referências}

Abrahão, G. R.; Asmus, M. Sistema de governança em Unidades de Conservação. Desenvolvimento e Meio Ambiente, 44, 104-117, 2018.

Ab'saber, A. N. Brasil: Paisagens de Exceção: o litoral e o pantanal mato-grossense patrimônios básicos. Cotia, SP: Ateliê Editorial, 2006.

Acselrad, H. Território e poder: a política das escalas. In: Fisher, T. (Org.). Gestão do desenvolvimento e poderes locais: marcos teóricos e avaliação. Salvador: Casa da Qualidade, 2002, p. 33-44.

Bachelard, G. O novo espírito científico. Rio de Janeiro: Tempo Brasileiro, 1995.

Brasil. Lei Federal no 6.938/1981. Política Nacional de Meio Ambiente.

Brasil. Lei Federal $n^{\circ} 7.661 / 1988$. Plano Nacional de Gerenciamento Costeiro. 
Brasil. Ministério do Meio Ambiente. Macrodiagnóstico da zona costeira do Brasil na escala da União. Brasília: MMA, UFRJ, LAGET, 1996. 280 p.

Brasil. Ministério do Meio Ambiente. Projeto Orla: Subsídios para um Projeto de Gestão. Brasília: MMA; MPO, 2004.

Brasil. Ministério do Meio Ambiente Ministério do Planejamento, Orçamento e Gestão. Projeto Orla: Guia de Implementação. Brasília: 2005. 36 p.

Brasil. Ministério do Meio Ambiente Ministério do Planejamento, Orçamento e Gestão. Projeto Orla: Implementação em Territórios com Urbanização Consolidada. Brasília: 2006a. 78 p.

Brasil. Ministério do Meio Ambiente Ministério do Planejamento, Orçamento e Gestão. Projeto Orla: Manual de Gestão. Brasília: 2006b. 88 p.

Brasil. Ministério do Meio Ambiente Ministério do Planejamento, Orçamento e Gestão. Projeto Orla: Fundamentos para Gestão Integrada. Brasília: 2006c. 74p.

Broc, N. Nationalisme, colonialisme et géographie: Marcel Dubois (1856-1916), Annales de Géographie, 545-568, 1974.

Bursztyn, M. Think locally, act globally: new challenges to environmental governance. Cambridge: Harvard University, 2009.

Capra, F. A Teia da Vida. Uma nova compreensão científica dos sistemas vivos. 9. ed. São Paulo: Cultrix, 2004.

Carlson, L.; Berkes, F. Co-management: concepts and methodological implications. Journal of Environmental Management, 75, 65-76, 2005.

Castro, I. E. Problemas e alternativas metodológicas para a região e o lugar. In: Souza, M. A. et al. (Org.). Natureza e sociedade de hoje: uma leitura geográfica. São Paulo: Hucitec, 1993.

Chapin III, F. S.; Folke, C.; Kofinas, G. P. A Framework for Understanding Change. In: Chapin III, F. S.; Folke, C.; Kofinas, G. P. (Eds.). Principles of Ecosystem Stewardship: Resilience-Based Natural Resource Management in a Changing World. Fairbanks: [s.n.]. 2009, p. 1-28.
Cleaver, F. The inequality of social capital and the reproduction of chronic poverty. World Development, 33(6), 2005.

Comission of the European Communities Roadmap for Maritime Spatial Planning: Achieving Common Principles in the EU. Brussels, 2008.

Corrêa, R. L. Organização espacial: dimensões, processos, forma e significado. Geografia, 36, Número Especial, 7-16, 2011.

Da Pozzo, C. Laws of the Sea - Toward a New Geography. Marine Pollution Bulletin, 18(7), 376-377, 1987.

Dallabrida, V. R. A gestão territorial através do diálogo e da participação. Scripta Nova, XI(245), 2007. Disponível: http://www.ub.es/geocrit/sn/sn-24520.htm

Diegues, A. C. A pesca construindo sociedades: leituras em antropologia marítima e pesqueira. São Paulo: NUPAUB, 2004.

Fletcher, S.; Smith, H. D. Geography and Coastal Management. Coastal Management, 419-427, 2007.

Floriani, D. Disciplinaridade e construção interdisciplinar do saber ambiental. Desenvolvimento e Meio Ambiente, 10, 33-37, 2004.

Fonseca, I. F.; Burstzyn, M. A banalização da sustentabilidade: reflexões sobre governança ambiental em escala local. Sociedade e Estado, 24(1), 17-46, 2009.

Francalanci, G.; Scovazzi, T. Lines in the Sea. Norwell: Kluwer Academic Publishers, 1994.

Frèmont, A. A região, espaço vivido. Coimbra: Almedina, 1980.

Fuks, M.; Perissinoto, R. Recursos, decisão e poder: Conselhos Gestores de Políticas Públicas de Curitiba. Revista Brasileira de Ciências Sociais, 21(60), 67-81, 2006.

Gandra, T. B. R.; Bonetti, J.; Scherer, M. E. G. Onde estão os dados para o Planejamento Espacial Marinho (PEM)? Análise de repositórios de dados marinhos e das lacunas de dados geoespaciais para a geração de descritores para o PEM do Sul do Brasil. Desenvolvimento e Meio Ambiente, 44, 405-421, 2018.

Grindle, M. Good enough governance revisited. Develop- 
ment Policy Review, 25(5), 553-574, 2007.

Haesbaert, R. O mito da desterritorialização: do "fim dos territórios" à multiterritorialidade. Rio de Janeiro: Bertrand Brasil, 2004.

Harley, J. B. Maps, knowledge, and power. In: Cosgrove, D.; Daniels, S. (Orgs.). The iconography of landscape: essays on the symbolic representation, design and use of past environments. Cambridge: Cambridge University Press, 1988, p. 277-312.

Holling, C. S.; Berkes, F.; Folke, C. Science, sustainability and resource management. In: Berkes, F.; Folke, C. Linking social and ecological systems. Cambridge, UK: Cambridge University Press, 1998, p. 342-361.

Hutter, L. M. Navegação nos Séculos XVII e XVIII. Rumo: Brasil. São Paulo: Edusp, 2005.

Inadmar A.; de Jode, H.; Lindsay, K.; Cobb, S. Capitalizing on nature: protected area management. Science, 283, p. 1856-1857, 1999.

Lacoste, Y. A Geografia. Isso serve, em primeiro lugar, para fazer a guerra. Campinas: Papirus, 2010.

Lins-de-barros, F. M.; Muehe, D. Tradição da Geografia nos Estudos Costeiros. Mercator, 8(16), 77-102, 2009. Disponível em: <http://www.mercator.ufc.br/mercator/ article/view/214>.

Machado, L. O. Angra dos Reis: Porque olhar para o passado. Diagnóstico socioambiental do município de Angra dos Reis. Rio de Janeiro: convênio Furnas-UFRJ, 1995.

Mackinder, H. J. Democratic Ideals and Reality: A Study in the Politics of Reconstruction. 1942.

Massé, P. O plano, aventura calculada. Lisboa: Moraes, 1967.

Massey, D. For Space. London: Sage, 2005.

Medeiros, R. P. Possibilidades e obstáculos à co-gestão adaptativa de sistemas pesqueiros artesanais: estudo de caso na área da Baia de Tijucas, litoral centro-norte de Santa Catarina no período de 2004 a 2008. Tese (Doutorado em Sociologia Política), Universidade Federal de Santa Catarina, Florianópolis, 2009.
Medeiros, R. P.; Serafini, T. Z.; Mcconney, P. Fortalecendo o ecosystem stewardship na pesca artesanal: perspectivas para a América Latina e Caribe. Desenvolvimento e Meio Ambiente, 32, 181-191, 2014.

Mello-Théry, N. A. Diálogos de saberes, factível? Geografia e interfaces de conhecimento: debates contemporâneos sobre ciência, cultura e ambiente. In: Salvi, R. F.; Marandola Jr. E. (Orgs.). Eduel: 2011.

Mitchell, G. O Ambiente Marinho sob a Perspectiva do Espaço e do Lugar. Redescobrindo o Brasil: 500 anos depois. In: Castro, I. E.; Miranda, M.; Egler, C. (Orgs.). Rio de Janeiro: Bertrand Brasil/Faperj, 1999.

Moraes, A. C. R. Geografia, pequena história crítica. $15^{\mathrm{a}}$ ed. SP: Hucitec: 1997.

Moraes, A. C. R. A gênese da geografia moderna. São Paulo: Hucitec, 1989.

Morin, E. Ciência com consciência. Rio de Janeiro: Bertrand, 2003

Morin, E. Introdução ao Pensamento Complexo. Instituto Piaget, Lisboa, 2008.

Muehe, D. Geografia Marinha: a retomada do espaço perdido. Revista da ANPEGE, 12(18), 185-210, 2016.

Muehe, D. A geomorfologia costeira e seu desdobramento para a Geografia Costeira e Marinha. Revista Brasileira de Geografia, 63(1), 29-59, 2018.

Nicolescu, B. O Manifesto da Transdisciplinaridade. Tradução Lúcia Pereira de Souza. São Paulo: TRIOM, 1999.

Nicolodi, J. L.; Asmus, M.; Turra, A.; Polette, M. Avaliação dos Zoneamentos Ecológicos-econômicos costeiros (ZEEC) do Brasil: proposta metodológica. Desenvolvimento e Meio Ambiente, 44, 378-404, 2018.

Peppoloni, S.; Di Capua, G. The meaning of Geoethics. Ethical challenges and case studies in Earth Sciences, pp. 3-14, Elsevier: 2015.

Pickaver, A. H.; C. Gilbert; F. Breton. An indicator set to measure the progress in the implementation of integrated coastal zone management in Europe. Ocean \& Coastal Management, 47(9), 449-462, 2007. 
Plasman, C. Implementing Marine Spatial Planning: A policy perspective. Marine Policy, 32, 811-815, 2008.

Prestes, L. D.; Pereira, L. F. C.; Gruber, N. L. S. Métodos para avaliar efetividade de gestão: o caso particular das Áreas de Proteção Ambiental (APAs). Desenvolvimento e Meio Ambiente, 44, 340-359, 2018.

Racine, J. B.; Raffestin, C.; Ruffy, V. Escala e ação, contribuições para uma interpretação do mecanismo de escala na prática da Geografia. Revista Brasileira de Geografia, 45(11), 123-135, 1983.

Raffestin, C. Por uma Geografia do Poder. São Paulo: Ática, 1993.

Ranciére, J. Ten thesis on Politics, Theory \& Event 5 (3), p.17-34, 2001.

Ratzel, F. La terra et la vie. Geografia comparativa, Torino 2 Vol. 1907.

Santos, M. Economia Espacial. 2a Edição (1979). São Paulo: Edusp, 2003.

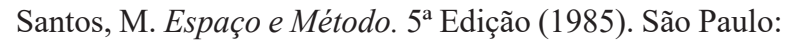
Edusp, 2008a.

Santos, M. A Natureza do espaço: Técnica e tempo razão e emoção. $4^{\text {a }}$ Reimpressão (1996). São Paulo: Edusp, 2008 b.

Santos, M. Técnica, Espaço, Tempo - Globalização e Meio Técnico-científico informacional. $5^{\text {a }}$ Ed. (1994) São Paulo: Edusp, 2008c.

Santos, M.; Bernardes, A.; Zerbini, A.; Gomes, C.; Bicudo, E.; Almeida, E.; Contel, F. B.; Grimm, F.; Nobre, G.; Antogiovanni, L.; Pinheiro, M. B.; Xavier, M.; Silveira, M. L.; Montenegro, M.; Rocha, M. F.; Arroyo, M.; Borin, P.; Ramos, S.; Belo, V. L O papel ativo da geografia: um manifesto. XII Encontro Nacional de Geógrafos. Florianópolis, 2000.

Saquet, M. A. Abordagens e concepções de território. São Paulo: Expressão Popular, 2007.

Silva, F. F.; Pellin, V. O desafio da sustentabilidade em economias periféricas. Seminário Internacional sobre Desenvolvimento Regional, UNISC, 2015.

Smith, N. New globalism, new urbanism: gentrification as global urban strategy. Antipode, 34(3), 427-450, 2002.

Soja, E. W. Geografias pós-modernas: a reafirmação do espaço na teoria social crítica. Trad. V. Ribeiro. Rio de Janeiro: Jorge Zahar, 1993.

Sonnic, E. Une activité touristique et de loisir amphibie entre espaces de pratiques et territoires de gestion: la plaisance. Confins, 8, 2010.

Sorre, M. Les fondaments de la géographie humane. Paris: Colin, 1954.

Sousa, E. E.; Serafini, T. Z. Panoramas das Unidades de Conservação na zona costeira e marinha do Estado de São Paulo. Desenvolvimento e Meio Ambiente, 44, 360-377, 2018.

Staden, H. Duas viagens ao Brasil: primeiros registros sobre o Brasil. Trad.: Angel Bojadsen. Porto Alegre: LP\&M, 2009.

Swyngedouw, E. Neither global nor local: 'glocalization'and the politics of scale. Spaces of globalization: Reasserting the power of the local, v. 1, 1997.

Teh, L. C. L.; Teh, L. S. L. A fuzzy logic approach to marine spatial management. Environmental Management, 47(4), 536-545, 2011.

Telles, D. H. Q. Possibilidades de reorganização territorial apoiada na imagem náutica a partir de Angra dos Reis/ $R J$. Tese de Doutorado, Faculdade de Filosofia, Letras e Ciências Humanas, Doutorado em Geografia Humana. Universidade de São Paulo. 2012.

Telles, D. H. Q.; Gândara, J. M. G.; Fontoura, L.; Sperb, M. Gestión Territorial y Planificación Participativa en la Ilha do Mel - Brasil: Conceptos y Prácticas. Estudios y Perspectivas en Turismo, 20, 2011.

Thrush, S. F.; Lewis, N.; Heron, R. L.; Fischer, K. T.; Lundquist, C. J.; Hewit, J. Addressing surprise and uncertain futures in marine science, marine governance, and society. Ecology and Society, 21(2), 44, 2016.

Tintoré, J.; Medina, R.; Gómez-Pujol, L.; Orfila, A.; Vizoso, G. Integrated and interdisciplinary scientific approach to coastal management. Ocean and Coastal Management, 52, 493-505, 2009. doi:10.1016/j.ocecoaman.2009.08.002

Vallega, A. The Regional Scale of Ocean Management and 
Marine Region Building. Ocean \& Coastal Management, 24, 17-37, 1994.

Vallega, A. Ocean geography for ocean Science. GeoJournal. 47, 511-522, 1999.

Vivero, J. L. S. El espacio maritimo en la geografia humana. GeoCrítica - Cuadernos Críticos de Geografia Humana, IV(20), 1979.
Vivero, J. L. S.; Mateos, J. C. R.; Sacchetti, E. Canada y el gobierno de los oceanos: el espacio marítimo em um estado descentralizado. Scripta Nova Revista Electrónica de Geografia y Ciencias Sociales, XIV(310). 2010.

Yázigi, E. Deixe sua estrela brilhar: criatividade nas ciências humanas e no planejamento. São Paulo: CNPq/ Plêiade, 2005. 